05

\title{
Резистивное переключение в отдельных ферромагнитных филаментах мемристорных структур на основе $\mathrm{ZrO}_{2}(\mathrm{Y}) / \mathrm{Ni}$
}

\author{
() Д.А. Антонов, ${ }^{1}$ Д.О. Филатов, ${ }^{1}$ А.С. Новиков, ${ }^{1}$ А.В. Круглов, ${ }^{1}$ И.Н. Антонов, ${ }^{1}$ А.В. Здоровейщев, ${ }^{2}$ \\ О.Н. Горшков \\ ${ }^{1}$ Нижегородский государственный университет им. Н.И. Лобачевского, \\ 603950 Нижний Новгород, Россия \\ ${ }^{2}$ Научно-исследовательский фризико-технический институт ННГУ им. Н.И. Лобачевского, \\ 603950 Нижний Новгород, Россия \\ e-mail: antonov.dmitr@inbox.ru
}

Поступило в Редакцию 12 апреля 2021 г.

В окончательной редакции 12 апреля 2021 г.

Принято к публикации 12 апреля 2021 г.

\begin{abstract}
Экспериментально изучен эффект резистивного переключения отдельных ферромагнитных филаментов мемристорных структур на основе функциональных слоев $\mathrm{ZrO}_{2}(\mathrm{Y}) / \mathrm{Ni}$. В качестве верхнего прижимного электрода виртуальной мемристорной структуры выступал проводящий зонд атомно-силового микроскопа. Обнаруженные особенности резистивного переключения биполярного типа связаны с разрушением и восстановлением филаментов, содержащих атомы $\mathrm{Ni}$, в диэлектрической пленке $\mathrm{ZrO}_{2}(\mathrm{Y})$ и предположительно обусловлены разной степенью металлизации филамента. Сформированные филаменты проявляются на изображениях, полученных с помощью магнитно-силовой микроскопии, как однодоменные ферромагнитные частицы.
\end{abstract}

Ключевые слова: мемристор, резистивное переключение, атомно-силовая микроскопия, ферромагнитные филаменты.

DOI: $10.21883 / J T F .2021 .10 .51359 .105-21$

\section{Введение}

Память произвольного доступа с проводящими мостиками (анг. conductive bridge) активно исследуется для применения в качестве энергонезависимой памяти следующего поколения [1-3]. В последние годы проявился повышенный интерес к возможности управления резистивным переключением (РП) в мемристорах путем воздействия магнитного поля $[4,5]$. Такая возможность обеспечивает повышенную функциональность мемристоров, позволяя за счет приложения внешнего магнитного поля изменять токонесущую способность проводящего филамента в диэлектрическом слое мемристорной структуры (эффект магнетосопротивления) [6,7]. Другой подход заключается в формировании в функциональном диэлектрике проводящих филаментов, содержащих атомы ферромагнитного материала (Co, $\mathrm{Ni}, \mathrm{Fe})$ [8]. Это может позволить управлять магнитными свойствами мемристора за счет приложения к структуре как магнитного, так и электрического поля. Один из способов реализации такого подхода - создание, по крайней мере, одного из электродов мемристорной структуры из ферромагнитного металла [9]. В этом случае возможно формирование катионов ферромагнитного материала за счет электрохимической реакции анодного окисления на границе раздела ферромагнитного электрода с диэлектрической прослойкой и последующим формированием филаментов из ферромагнитного металла в электрическом поле между электродами мемристорной структуры [10].
С другой стороны, одной из проблем в разработке мемристорных устройств энергонезависимой памяти является проблема масштабирования [11]: закономерности РП, установленные при исследованиях модельных мемристров с размерами электродов, под которыми может формироваться большое количество филаментов, оказываются отличными от закономерностей РП мемристоров с электродами нанометровых размеров, под которыми может сформироваться только один филамент.

В настоящей работе приводятся результаты экспериментальных исследований механизмов формирования отдельных проводящих ферромагнитных филаментов из атомов ферромагнитного металла и особенностей РП отдельных проводящих филаментов мемристорных структур на основе функциональных слоев $\mathrm{ZrO}_{2}(\mathrm{Y}) / \mathrm{Ni}$. В качестве верхнего прижимного электрода мемристорной структуры используется проводящий зонд атомносилового микроскопа (АСМ). Такое устройство (виртуальный составной мемристор) является хорошей модельной системой для изучения РП [12], так как латеральный размер контакта АCМ зонда к диэлектрику $<10 \mathrm{~nm}$, что сопоставимо с размерами филаментов в перспективных мемристорных устройствах.

\section{1. Методика эксперимента}

Пленки $\quad \mathrm{ZrO}_{2}(\mathrm{Y}) \quad\left(\sim 12 \%\right.$ mol. $\left.\quad \mathrm{Y}_{2} \mathrm{O}_{3}\right) \quad$ толщиной $\sim 10 \mathrm{~nm}$ формировались методом высокочастотного 


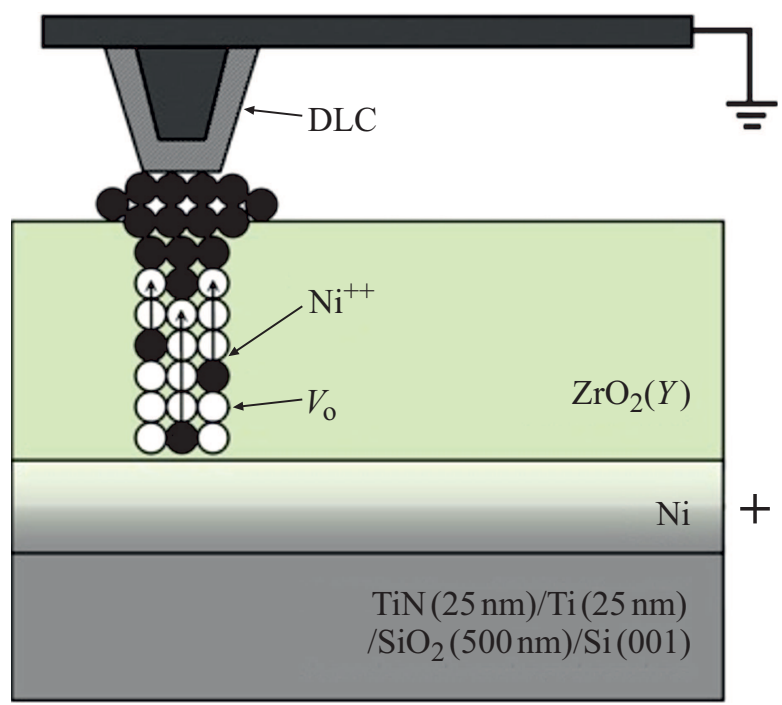

Рис. 1. Схема формирования ферромагнитных филаментов и исследования эффекта РП в пленках $\mathrm{ZrO}_{2}(\mathrm{Y}) / \mathrm{Ni}$.

магнетронного осаждения на стандартных подложках $\mathrm{TiN}(25 \mathrm{~nm}) / \mathrm{Ti}(25 \mathrm{~nm}) / \mathrm{SiO}_{2}(500 \mathrm{~nm}) / \mathrm{Si}(001)$ с предварительно осажденным на них слоем Ni толщиной $\sim 10 \mathrm{~nm}$, а также без слоя $\mathrm{Ni}$ (образцы-спутники). Формирование проводящих филаментов в мемристорных структурах, исследование РП в них, а также исследование их микромагнитных свойств проводилось при помощи АСМ NT-MDT Solver Pro. Формирование ферромагнитных филаментов проводилось с использованием АСМ зондов марки HA HR DCP с электропроводящим алмазоподобным покрытием путем подачи пилообразных импульсов электрического напряжения между АСМ зондом и слоем $\mathrm{Ni} V_{g}(t)$ амплитудой $\sim 8 \mathrm{~V}$ и длительностью
$6 \mathrm{~s}$ (рис. 1). При этом контролировалась сила тока, протекающего через $\mathrm{ACM}$ зонд, пленку $\mathrm{ZrO}_{2}(\mathrm{Y})$ и слой $\mathrm{Ni}\left(I_{t}\right)$. Исследование эффекта РП проводилось путем измерения и анализа циклических ВАХ контакта АСМ зонда к пленкам $\mathrm{ZrO}_{2}(\mathrm{Y}) / \mathrm{Ni}$. Исследование магнитных свойств сформированных филаментов проводилось методом магнитно-силовой микроскопии (МСМ) с использованием зондов марки NT-MDT HA_FM_CoFe.

\section{2. Результаты и обсуждение}

Формирование проводящих филаментов, содержащих атомы $\mathrm{Ni}$, проводилось с помощью зонда АСМ. Для этого зонд приводился в контакт с поверхностью пленки $\mathrm{ZrO}_{2}(\mathrm{Y}) / \mathrm{Ni}$ в контактном режиме $\mathrm{ACM}$ и измерялись циклические вольт-амперные характеристики (BAX). Обычно первые 5-20 циклических ВАХ демонстрировали ассиметричные петли гистерезиса биполярного типа (рис. 2, a, замкнутая кривая 1), обусловленные формированием/разрушением проводящих филаментов, преимущественно состоящих из вакансий кислорода в $\mathrm{ZrO}_{2}(\mathrm{Y})$, электронная проводимость по которым осуществляется по прыжковому механизму [13]. Затем характер проводимости существенно менялся: электропроводность виртуальной мемристорной структуры в состоянии с низким сопротивлением (LRS) резко возрастала (рис. 2, a, замкнутая кривая 2). Одновременно увеличивалась ширина петли гистерезиса.

Вид ВАХ, представленный на рис. 2, $a$ (замкнутая кривая 2), типичен для мемристоров типа „проводящий мостик“ (англ. Conducting Bridge) [7]. Резистивное переключение подобных устройств основано на разрушении и восстановлении проводящих филаментов, состоящих из атомов металлов, в диэлектрической пленке в результате окислительно-восстановительных реакций (преиму-
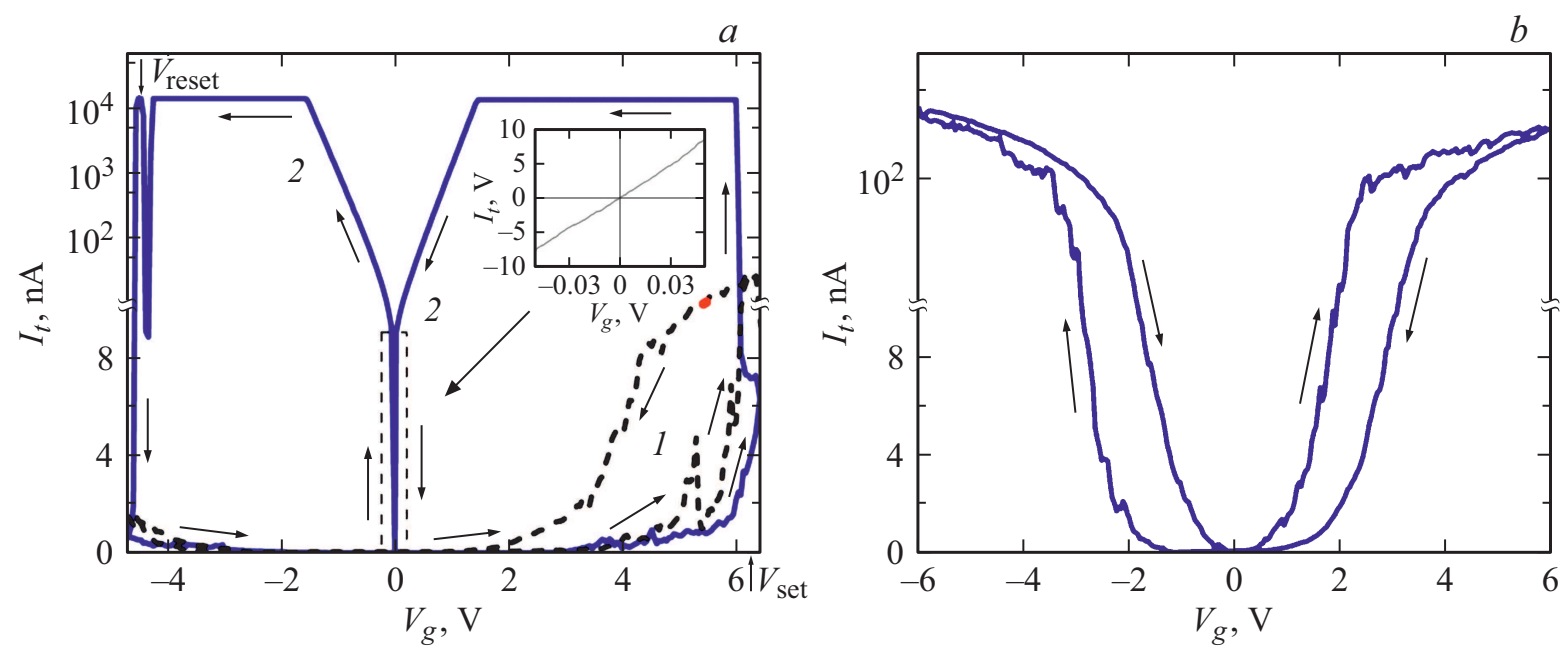

Рис. 2. $\mathrm{BAX}$ контакта $\mathrm{ACM}$ зонда к пленке $\mathrm{ZrO}_{2}(\mathrm{Y}) / \mathrm{Ni}(a)$ и пленке $\mathrm{ZrO}_{2}(\mathrm{Y})$ без слоя $\mathrm{Ni}(\boldsymbol{b})$. Ограничение тока выше уровня $1 \cdot 10^{4} \mathrm{nA}(a)$ связано с током насыщения усилителя АСМ. Вставка на рисунке $a-$ участок вольт-амперной зависимости мемристорной структуры в LRS (замкнутая кривая 2) вблизи 0 в линейном масштабе. 

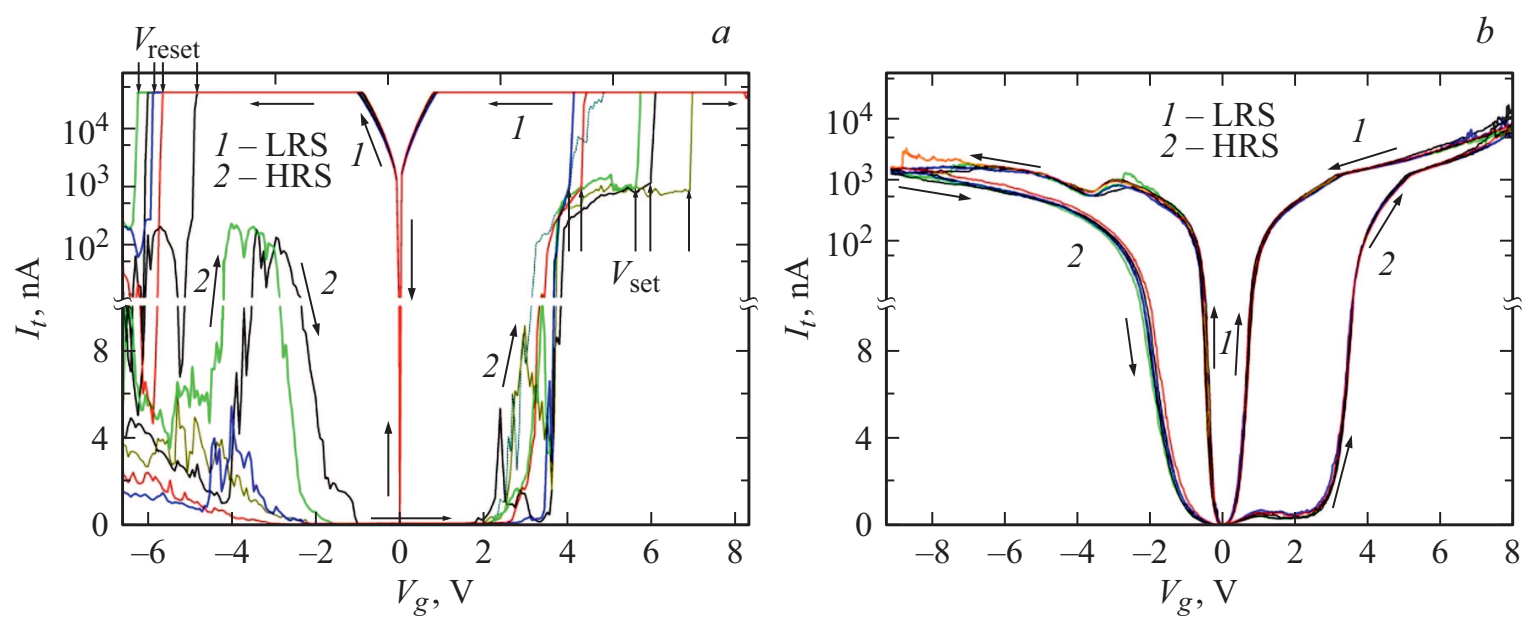

Рис. 3. Два вида циклических $\mathrm{BAX}$ (приведено по 5 циклов) контакта $\mathrm{ACM}$ зонда к пленке $\mathrm{ZrO} 2(\mathrm{Y}) / \mathrm{Ni}: a-$ в режиме формирования/разрушения металлизированных филаментов; $b$ - металлизация филамента прошла не полностью. Ограничение тока выше уровня $1 \cdot 10^{4} \mathrm{nA}(a)$ связано с током насыщения усилителя ACM. LRS - состояние с низким сопротивлением, HRS - состояние с высоким сопротивлением.
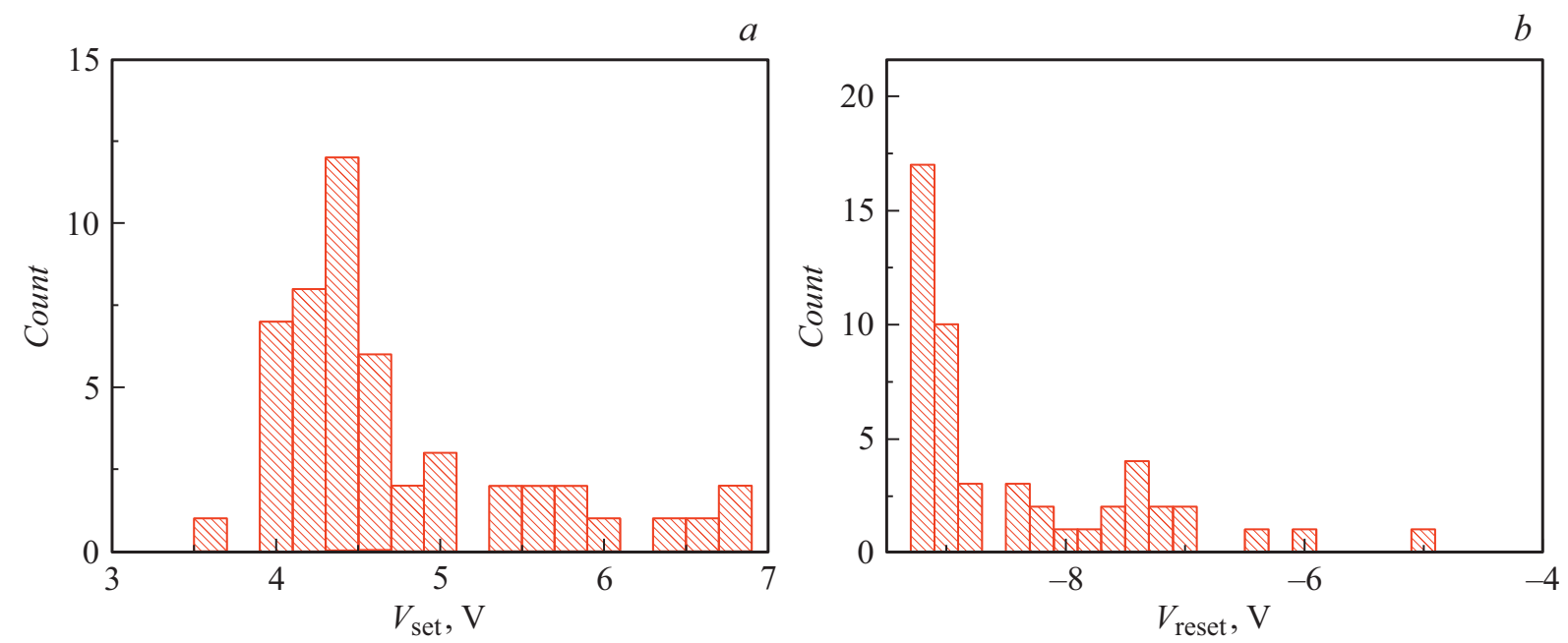

Рис. 4. Гистограммы распределения $V_{\text {set }}(a)$ и $V_{\text {reset }}(b)$ виртуальной мемристорной структуры на основе пленки $\mathrm{ZrO} 2(\mathrm{Y}) / \mathrm{Ni}_{\text {в }}$ режиме формирования металлизированных филаментов.

щественно областей интерфейсов металл/диэлектрик) под действием электрического поля [10]. Качественно механизм формирования метализированного филамента, содержащего атомы $\mathrm{Ni}$, можно описать следующим образом: при приложении положительного потенциала к нижнему активному Ni-электроду относительно верхнего электрода (АСМ зонда) ионы $\mathrm{Ni}^{2+}$ на границе слоя металла с оксидом, где они образуются за счет электрохимической реакции окисления, переносятся в оксид путем электродиффузии, где, двигаясь в направлении к АСМ зонду, восстанавливаются на нем, формируя проводящий металлизированный филамент, замыкающий нижний электрод и АCM зонд („SET“ процесс). При этом возникшие в начале измерений филаменты из вакансий кислорода в оксиде могут облегчать дрейф ионов металла и, таким образом, способствовать фор- мированию металлических филаментов. Мы полагаем, что латеральные размеры формирующихся филаментов по порядку величины соответствуют размерам области контакта острия АСМ зонда к поверхности образца (латеральный размер $<10 \mathrm{~nm}$ [13]). На образцах-спутниках (без слоя $\mathrm{Ni}$ ) наблюдались только нелинейные циклические BAX (рис. 2, $b$ ), соответствующие формированию и разрушению филаментов из вакансий кислорода в оксидном слое (так называемые окислительновосстановительные или RedOx процессы - от английского Reduction-Oxidation) [14].

Циклические BAX контакта АСМ зонда к поверхности слоев $\mathrm{ZrO}_{2}(\mathrm{Y}) / \mathrm{Ni}$ после формирования $\mathrm{Ni}$ филамента (процедуры формовки) демонстрировали устойчивое резистивное переключение биполярного типа с петлей гистерезиса двух видов (рис. 3). При этом оба вида ВАХ 

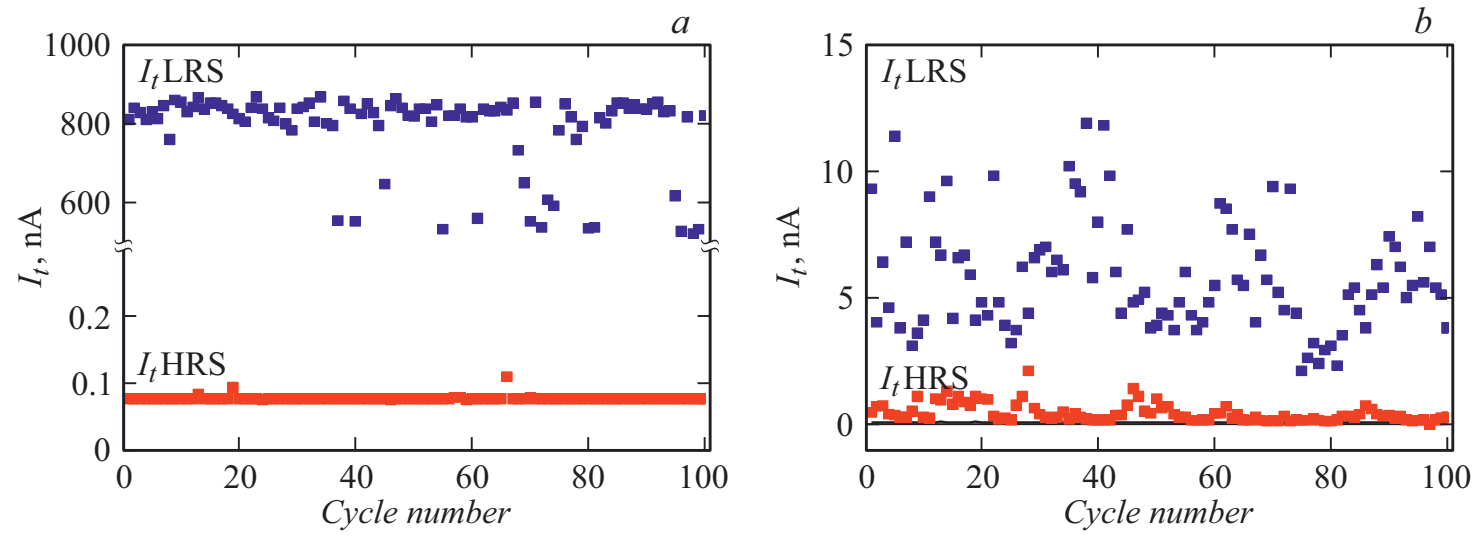

Рис. 5. Динамика изменения значений $I_{\mathrm{LRS}}$ и $I_{\mathrm{HRS}}$ в процессе 100 циклов переключений в режиме формирования/разрушения металлизированных филаментов $(a)$ при $V_{g}=0.5 \mathrm{~V}$ в случае, когда металлизация филамента прошла не полностью $(b)$.

$a$

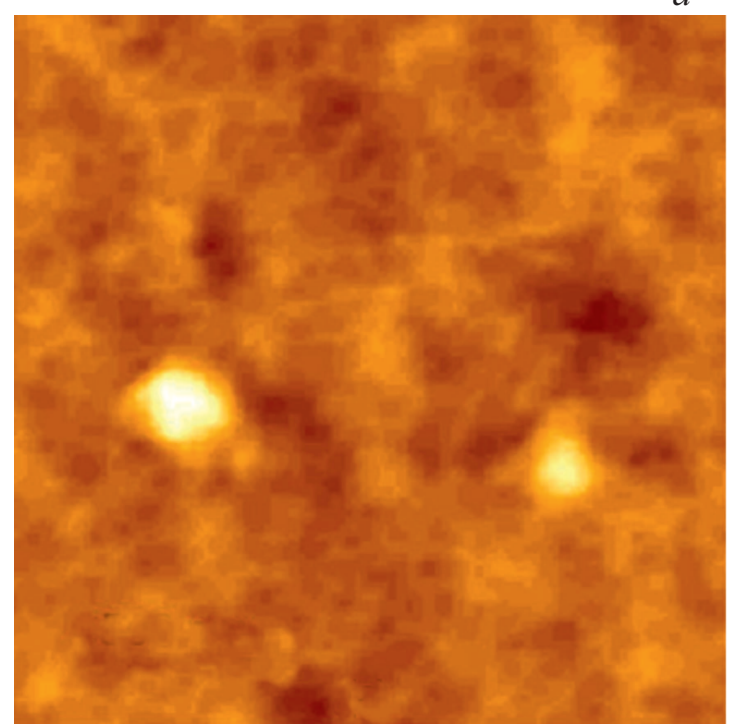

$500 \mathrm{~nm}$

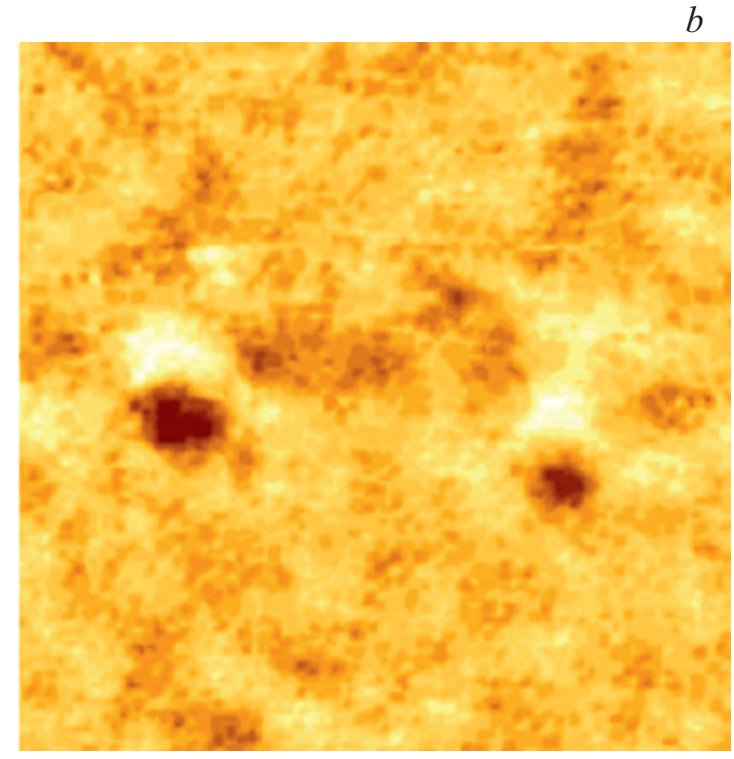

$b$

Рис. 6. Морфология (a) и МСМ контраст $(b)$ поверхности пленки $\mathrm{ZrO}_{2}(\mathrm{Y}) / \mathrm{Ni}$ после формирования двух проводящих филаментов.

могут наблюдаться на одном виртуальном мемристорном устройстве и определяться выбором развертки по напряжению, прикладываемому между АСМ зондом и образцом. Циклические ВАХ, приведенные на рис. 3, $a$, связываются нами с формированием/разрушением металлизированных филаментов, замыкающих $\mathrm{Ni}$-слой на ACM зонд. Отношение токов, протекающих через структуру в LRS и в состоянии с высоким сопротивлением (HRS), $\left(I_{\mathrm{LRS}} / I_{\mathrm{HRS}}\right)>5000$ при $V_{g}=0.5 \mathrm{~V}$. Разброс основных параметров РП, наблюдаемый на циклических ВАХ, представленных на рис. 3, $a$, обусловлен тем, что в связи со стохастическим характером формирования структуры филамента не воспроизводится и его предыдущая токонесущая способность. В том числе может реализоваться не полная „металлизация“ филамента. В этом случае проводимость обусловлена смешанным или активационным характером проводимости в зависи- мости от толщины диэлектрической прослойки между филаментом и АСМ зондом (рис. 3,b). Среднее отношение токов при этом $\left\langle I_{\mathrm{LRS}} / I_{\mathrm{HRS}}\right\rangle \sim 10$ при $V_{g}=0.5 \mathrm{~V}$. Гистограммы распределения основных параметров РП $\left(V_{\text {set }}, V_{\text {reset }}\right)$, построенные на основе анализа 50 циклических BAX в режиме формирования/разрушения металлизированного филамента, приведены на рис. 4.

Установлено, что значение $V_{\text {set }}$ для таких мемристорных структур меняется в диапазоне от 3.5 до $7 \mathrm{~V}$ (рис. $4, a)$. В свою очередь, гистограмма распределения Vreset (рис. 4, $b$ ) демонстрирует, что электрическое напряжение переключения в отрицательной области меняется в диапазоне от -9.2 до $-5 \mathrm{~V}$ и имеет два максимума при $V_{g}=-9.2$ и $=-7.5 \mathrm{~V}$.

На рис. 5 показана динамика изменения значений $I_{\mathrm{LRS}}$ и $I_{\mathrm{HRS}}$ в процессе 100 циклов переключений в режиме формирования/разрушения металлизированных фи- 
ламентов (рис. 5,a) и в случае, когда металлизация филамента прошла не полностью (рис. 5, $b$ ).

Из представленных результатов следует, что в исследованном устройстве с металлическим проводящим филаментом возможна реализация минимум двух проводящих состояний. РП в таком устройстве обусловлено двумя различными механизмами проводимости (металлический, активационный).

Исследование магнитных свойств сформированных филаментов проводилось методом МСМ. Морфология поверхности пленки $\mathrm{ZrO}_{2}(\mathrm{Y}) / \mathrm{Ni}$ (рис. 6,a) в местах формирования металлизированных филаментов демонстрирует образование плоских островков с высотами $1-1.5 \mathrm{~nm}$ и латеральными размерами $100-150 \mathrm{~nm}$, которые проявляются на МСМ изображении (рис. 6, $b$ ) как однодоменные ферромагнитные частицы [15].

Это может быть связано со скоплением атомов $\mathrm{Ni}$ в приповерхностном слое пленки $\mathrm{ZrO}_{2}(\mathrm{Y})$ вблизи проводящего филамента в процессе его формирования. На МСМ изображениях образцов-спутников после формирования проводящих филаментов (в СНC) магнитного контраста от сформированных филаментов не наблюдалось.

\section{Заключение}

Таким образом, в работе экспериментально продемонстрирована возможность формирования при помощи АCM зонда виртуального мемристора на основе стабилизированного диоксида циркония $\mathrm{ZrO}_{2}(\mathrm{Y})$ с подслоем из $\mathrm{Ni}$ с проводящими филаментами из атомов $\mathrm{Ni}-$ „проводящий мостик“ (Conducting Bridge). Продемонстрирована возможность работы такого устройства в двух режимах $\left(I_{\mathrm{LRS}} / I_{\mathrm{HRS}} \sim 10\right.$ и $I_{\mathrm{LRS}} / I_{\mathrm{HRS}}>5000$ при $\left.V_{g}=0.5 \mathrm{~V}\right)$, предположительно связанных с разной степенью металлизации филамента в процессе РП. Сформированные проводящие филаменты, содержащие атомы $\mathrm{Ni}$ в функциональном слое $\mathrm{ZrO}_{2}(\mathrm{Y}) / \mathrm{Ni}$, обладают ферромагнитными свойствами и проявляются на МСM изображениях как однодоменные частицы.

\section{Благодарности}

Авторы благодарят А.А. Фраермана и И.Ю. Пашенькина, Институт физики микроструктур РАН, Нижний Новгород за полезную дискуссию.

\section{Финансирование работы}

Работа выполнена при поддержке гранта РФФИ № 2002-00830а в части формирования образцов, исследования РП, а также микромагнитных свойств сформированных филаментов и гранта РНФ № 18-72-10061 в части отработки методик формирования ультратонких металлоических слоев на поверхности проводящих подложек.

\section{Конфликт интересов}

Авторы заявляют, что у них нет конфликта интересов.

\section{Список литературы}

[1] X. Tian, S. Yang, M. Zeng, L. Wang, J. Wei, Z. Xu, W. Wang, X. Bai. Adv. Mater., 26 (22), 3649 (2014). DOI: 10.1002 /adma.201400127

[2] I. Valov, R. Waser, J.R. Jameson, M.N. Kozicki. Nanotechnology, 22, 254003 (2011). DOI: $10.1088 / 0957-4484 / 22 / 28 / 289502$

[3] J.J. Yang, D.B. Strukov, D.R. Stewart. Nat. Nanotechnol., 8, 13 (2013). DOI: 10.1038/nnano.2012.240

[4] H.J. Jang, O.A. Kirillov, O.D. Jurchescu, C.A. Richter. Appl. Phys. Lett., 100 (4), 43510 (2012). DOI: 10.1063/1.3679114

[5] F.Z. Wang, L. Li, L. Shi, H. Wu, L.O. Chua. J. Appl. Phys., 125 (5), 54504 (2019). DOI: 10.1063/1.5042281

[6] L. Li, Y. Liu, J. Teng, S. Long, Q. Guo, M. Zhang, Y. Wu, G. Yu, Q. Liu, H. Lv, M. Liu. Nanoscale Res. Lett., 12, 210 (2017). DOI: 10.1186/s11671-017-1983-2

[7] S. Otsuka, Y. Hamada, D. Ito, T. Shimizu, S. Shingubara. Jpn. J. Appl. Phys., 54 (5S), 05ED02 (2015). DOI: 10.7567/JJAP.54.05ED02

[8] Z. Yang, Q. Zhan, X. Zhu, Y. Liu, H. Yang, B. Hu, J. Shang, L. Pan, B. Chen, R.-W. Li. Europhys. Lett., 108 (5), 58004 (2014). DOI: 10.1209/0295-5075/108/58004

[9] S. Otsuka, Y. Hamada, T. Shimizu, S. Shingubara. Appl. Phys. A Mater. Sci. Process, 118, 613 (2015). DOI: $10.1007 / \mathrm{s} 00339-014-8769-5$

[10] M. Lubben, I. Valov. Adv. Electron. Mater., 5(9), 1800933 (2019). DOI: 10.1002/aelm.201800933

[11] S. Ambrogio, B. Magyari-Köpe, N. Onofrio, M.M. Islam, D. Duncan, Y. Nishi, A. Strachan. J. Electroceram., 39, 39 (2017). DOI: $10.1007 / \mathrm{s} 10832-017-0093-\mathrm{y}$

[12] M. Lanza, Conductive Atomic Force Microscopy: Applications in Nanomaterials (Weinheim: Wiley-VCH Verlag GmbH \& Co. KGaA, 2017)

[13] D.O. Filatov, D.A. Antonov, I.N. Antonov, A.P. Kasatkin, O.N. Gorshkov. J. Mater. Sci. Chem. Eng., 5, 8 (2017). DOI: $10.4236 /$ msce. 2017.51002

[14] R. Waser, J. Nanosci. Nanotechnol., 12, 7628 (2012). DOI: $10.1166 /$ jnn.2012.6652

[15] D.V. Ovchinnikov, A.A. Bukharaev. In: AIP Conf. Proceed., 696, 634 (2003). DOI: 10.1063/1.1639762 